Www.jmscr.igmpublication.org

Impact Factor 5.84

Index Copernicus Value: 83.27

ISSN (e)-2347-176x ISSN (p) 2455-0450

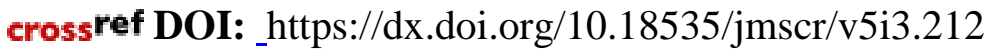

Journal Of Medical Science And Clinical Research

IGM Publication

An official Publication of IGM Publication

\title{
Comparison of Difficult Intubation and Neck Circumference to Thyromental Distance Ratio, in Obese and Non-Obese: A Clinical Study
}

\author{
Authors \\ Nadia Rose ${ }^{1}$, Dr Maya G' ${ }^{2}$, Dr Anil Sathyadas ${ }^{3}$ \\ ${ }^{1}$ Post Graduate Trainee, Thiruvananthapuram Govt. Medical College \\ ${ }^{2}$ Additional Professor, Thiruvananthapuram Govt Medical College \\ ${ }^{3}$ Assistant Professor, Thiruvananthapuram Govt Medical College
}

\begin{abstract}
Background: This study was conducted to assess whether intubation is more difficult in obese patients compared to non-obese and to assess the ability of ratio of the neck circumference to thyromental distance (NC/TM), to predict difficult intubation in obese patients.
\end{abstract}

Methods: This study is a cross sectional study. After obtaining institutional approval, consenting patients were enrolled in this study. The incidence of difficult tracheal intubation in 166 obese (BMI $25 \mathrm{~kg} / \mathrm{m2})$ and 166 non-obese patients was compared. Difficult intubation was determined using the Intubation Difficulty Scale (IDS $\geq 5$ ). Airway assessment indices were evaluated for their relation to IDS. NC/TM was calculated and its ability to predict difficult intubation in obese patients as well as non obese patients was assessed.

Results: Difficult intubation was more frequent in obese patients than in non-obese patients (14.5\% vs 7.2 $\% ; P=0.031) . N C / T M$ at a cut-off $\geq 4.99$ showed the high sensitivity, specificity and a positive likelihood ratio, and large area under the curve on ROC curve in the obese.

Conclusion: Difficult intubation defined by IDS were common in obese patients compared to non-obese. Neck circumference to thyromental distance ratio $\geq 4.99$ yielded a very high sensitivity, specificity and positive likelihood ratio in the obese group. Therefore, it may be used as a screening test for predicting difficult intubation in the obese.

Keywords: airway management; obesity; risk assessment; tracheal intubation.

\section{INTRODUCTION}

Airway management is undoubtedly one of the most important responsibilities of an anaesthesiologist, yet documentation of the clinical assessment, which is a professional requirement, is often incomplete. Careful airway assessment before the induction of anaesthesia is of utmost importance as poor airway management has been recognized as a serious patient safety concern for almost three decades. Although vast improvements in patient monitoring, airway devices, and clinical protocols and training have reduced the risk associated with an unpredicted difficult airway (DA), these advancements have not reduced the incidence of unexpected DAs in clinical practice.

The literature is rich with studies and metaanalyses attempting to determine the best single method or combination of methods to aid the anesthesiologist in predicting difficult intubation. Although there are numerous studies for anticipating difficult intubation, none is accurate. The diagnostic accuracy of these screening tests varies between different studies. This is attributed 
to difference in incidence of difficult laryngoscopy, inadequate statistical power, different test thresholds and differences in patient characteristics. ${ }^{1}$ Patient characteristics differ greatly due to race or ethnicity which may influence the incidence of difficult laryngoscopy and difficult intubation. The majority of studies of difficult laryngoscopy and intubation have been performed in the American or European population $^{1-5}$. Anthropometrically, Indians are different compared to the Americans or Europeans.

In Indian population, the incidence of difficult laryngoscopy and intubation was $9.7 \%$ and $4.5 \%$, respectively according to Smitha et $\mathrm{al}^{6}$. Adequate data of normal values in a given population may help the clinician to identify patients who are outside the range and therefore potentially challenging. Moreover, most studies do not provide a 'measure' of difficult intubation in patients with difficult laryngoscopy.

There are divided opinions regarding difficulty of intubation in obese and non-obese. One reason for these discrepancies is the lack of consensus on the definition of the term "difficult intubation," which varies among authors. The best way to predict a difficult intubation in obese patients remains debatable as body mass index (BMI) poorly predicts difficult intubation. This study is considering neck circumference to thyromental distance ratio as a predictor, assuming it can represent the neck soft tissue mass.

Intubation Difficulty Scale (IDS) has been used as a validated score for rating difficult intubation ${ }^{7}$. So in this study IDS is being used to compare ease of intubation in obese and non- obese.

The aims of this study were to compare difficult intubation in obese and non-obese using Intubation Difficulty Scale and to assess whether there is an association between neck circumference to thyromental distance ratio and difficult intubation.

\section{MATERIALS AND METHODS}

After getting approval from the Institutional Ethical Committee and written informed consent, 332 ASA (American Society of Anaesthesio- logists) 1 and 2 patients more than 18 years undergoing elective general anaesthesia with tracheal intubation were included in the study. It was a cross sectional study and purposive sampling technique was used. The sample size of the study was calculated based on the results obtained in the parent study -"Neck circumference to thyromental distance ratio: a new predictor of difficult intubation in obese patients"- $\mathrm{BJA}^{8}$, published in February 24, 2011.The sample size was found to be 166 in each group: obese and non-obese. According to WHO: Asia Pacific perspective- Redefining obesity $(2000)^{9}$, patients with a BMI of $\geq 25 / \mathrm{m}^{2}$ was assigned as obese. Those with an upper airway pathology (i.e. maxillofacial fractures, tumors, etc.), cervical spine fracture and those with thyroid swelling or other neck swelling were excluded from the sudy.

The patients were assessed in the Pre -anaesthetic clinic. Data collected was entered in a prestructured questionnaire. A previous history of difficult intubation was noted. Weight, height, neck circumference, mouth opening, thyromental distance and sterno mental distance was measured. Modified Mallampati classification, presence or absence of impaired temporomandibular joint mobility, retrognathia, limited neck movement (assessed by inability to extend and flex the neck to a range around $90^{\circ}$ ), and the presence or absence of abnormally protruding upper teeth were also recorded. The Wilson risk sum score was then calculated. Neck circumference was measured at the level of upper border of cricoid cartilage in the upright and seated position.

All patients were maintained in fasting state for about 6-8 hours and received premedication orally on previous night of surgery. In the operation theatre, the patients were positioned with cushion under the head with the neck extended, in the sniffing position. All routine monitors which included electrocardiogram, pulse oximetry, and non-invasive arterial pressure was used for each patient. Patients was pre-oxygenated with $100 \%$ oxygen through a facemask for $3 \mathrm{~min}$. Anaesthesia was then induced with propofol 1- 
$2.5 \mathrm{mg} / \mathrm{kg}$. Cricoid pressure was applied as described bySellick ${ }^{10}$ if it was requested by the anaesthesiologist for a better view at laryngoscopy. A Macintosh laryngoscope blade was used for the laryngoscopy in each case. All intubations were performed by anaesthesiologists who were blinded to the assignment of the patient.

The laryngoscopic view was graded according to Cormack and Lehane's scale. The outcome, difficulty of intubation was assessed using the Intubation Difficulty Scale in the operation theater. Those with an IDS score of $\geq 5$ and $<5$ were defined as the difficult and easy groups, respectively. Adverse outcomes were also noted.

\section{STATISTICAL ANALYSIS}

Data was analyzed using computer software "Statistical package for social sciences" (SPSS) ver-16 for windows. The differences between the obese and non-obese groups were analysed using Student's t-test. Differences between the difficult and easy groups in obese and non-obese were analysed using univariate analysis using chisquare test to determine the significant risk factors. The diagnostic performance of the risk factors were assessed using the receiver-operating characteristic (ROC) curves and adequate cut-off point identified by selecting the maximum specificity and sensitivity. A value of $\mathrm{P}<0.05$ was considered significant.

\section{RESULTS}

In each group intubation difficulty was assessed by the Intubation Difficulty Scale. The groups were compared with the several airway assessment variables to see if there was any association with difficult intubation.

TABLE: 01 COMPARISON OF DIFFICULT INTUBATION IN OBESE AND NON-OBESE

\begin{tabular}{|l|c|c|c|c|c|c|}
\hline \multirow{2}{*}{ IDS } & \multicolumn{4}{|c|}{ Category } & \multicolumn{2}{c|}{ Total } \\
\cline { 2 - 7 } & \multicolumn{2}{|c|}{ Obese } & \multicolumn{2}{c|}{ Non-obese } & $\mathrm{N}$ & $\%$ \\
\cline { 2 - 7 } & $\mathrm{N}$ & $\%$ & $\mathrm{~N}$ & $\%$ & 36 & 10.8 \\
\hline$\geq 5$ & 24 & 14.5 & 12 & 7.2 & 296 & 89.2 \\
\hline$<5$ & 142 & 85.5 & 154 & 92.8 & 332 & 100.0 \\
\hline Total & 166 & 100.0 & 166 & 100.0 & \\
$\chi^{2}=4.486$ & $\mathrm{df}=1$ & $\mathrm{p}=0.034$
\end{tabular}

TABLE: 02 COMPARISON OF NECK CIRCUMFERENCE TO THYROMENTAL DISTANCE RATIO IN OBESE AND NON-OBESE PATIENTS WITH IDS $\geq 5$

\begin{tabular}{|l|c|c|c|c|c|}
\hline \multirow{2}{*}{ Category } & \multirow{N}{*}{$\mathrm{N}$} & \multicolumn{2}{|c|}{$\mathrm{NC} / \mathrm{TM}$} & \multirow{2}{*}{$\mathrm{t}$} & $\mathrm{p}$ \\
\cline { 3 - 4 } & & Mean & $\mathrm{sd}$ & & \multirow{2}{*}{032} \\
\hline Obese & 24 & 5.53 & 0.91 & \multirow{2}{*}{2.231} & .032 \\
\hline Non obese & 12 & 4.62 & 1.56 & & \\
\hline
\end{tabular}

TABLE: 03 UNIVARIATE ANALYSIS COMPARING OBESE PATIENTS WITHIDS $\geq 5$ AND OBESE PATIENTS WITH IDS $<5$

\begin{tabular}{|c|c|c|c|c|c|c|}
\hline & \multicolumn{4}{|c|}{ IDS } & \multirow[b]{3}{*}{$\mathrm{t}$} & \multirow[b]{3}{*}{$\mathrm{p}$} \\
\hline & \multicolumn{2}{|c|}{$\geq 5(\mathrm{~N}=24)$} & \multicolumn{2}{|c|}{$<5(\mathrm{~N}=142)$} & & \\
\hline & mean & $\mathrm{sd}$ & mean & sd & & \\
\hline Age (years) & 59.0 & 10.6 & 51.5 & 13.1 & 2.658 & .009 \\
\hline Weight $(\mathrm{cm})$ & 76.4 & 8.9 & 81.2 & 7.3 & -2.889 & .004 \\
\hline Height $(\mathrm{cm})$ & 162.4 & 8.1 & 164.9 & 7.9 & -1.426 & .156 \\
\hline BMI $\left(\mathrm{kg} / \mathrm{m}^{2}\right)$ & 28.9 & 2.3 & 29.9 & 1.9 & -2.189 & .030 \\
\hline $\mathrm{NC}(\mathrm{cm})$ & 42.6 & 3.8 & 44.1 & 3.6 & -1.797 & .074 \\
\hline $\mathrm{TM}(\mathrm{cm})$ & 7.9 & 1.3 & 10.7 & 1.1 & -11.302 & $<0.001$ \\
\hline $\mathrm{NC} / \mathrm{TM}$ & 5.5 & .9 & 4.2 & .6 & 9.250 & $<0.001$ \\
\hline $\mathrm{SM}(\mathrm{cm})$ & 16.9 & 13.0 & 17.4 & 1.0 & -.428 & 669 \\
\hline Mouth opening in $\mathrm{cm}$ & 5.29 & 0.33 & 5.20 & 0.36 & 1.081 & .281 \\
\hline
\end{tabular}


ROC CURVE ANALYSIS OF SCREENING TESTS FOR DIFFICULT INTUBATION IN OBESE

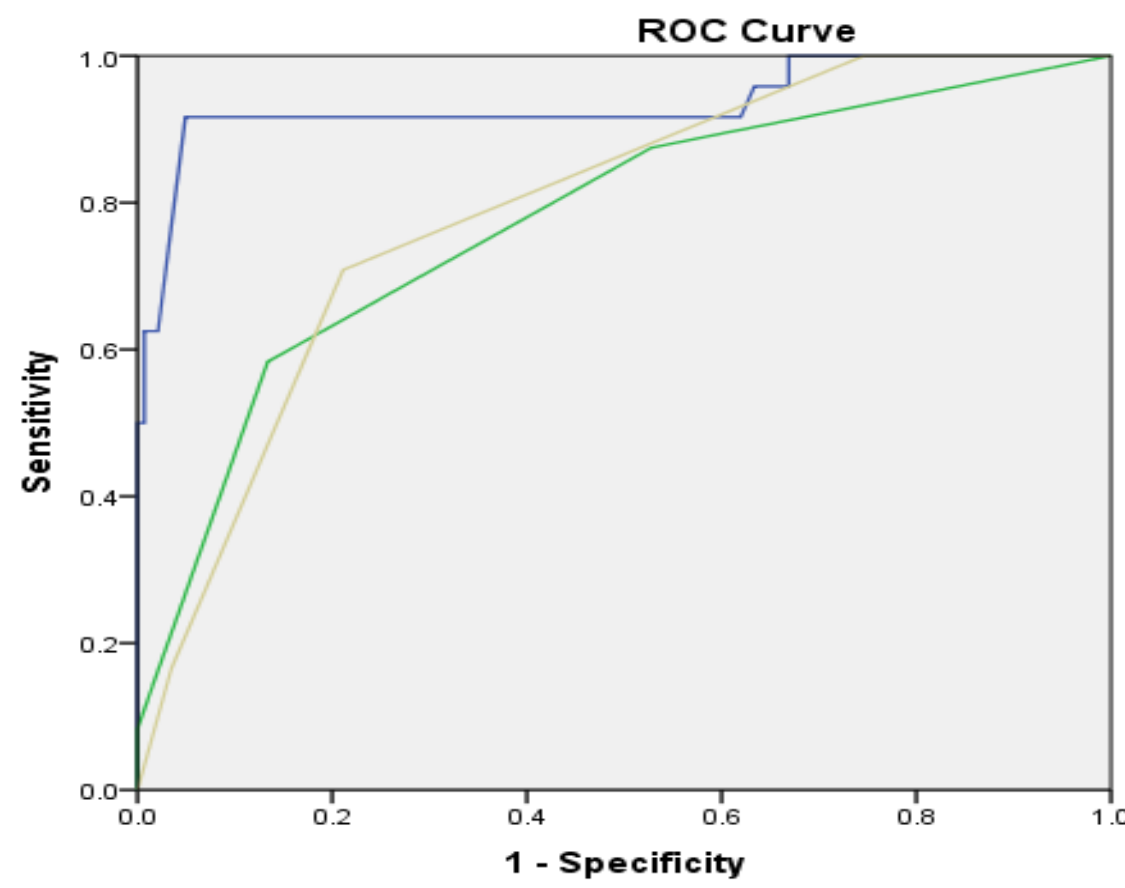

$$
\begin{aligned}
& \text { Source } \\
& \text { of the } \\
& \text { Curve } \\
& \text { NC/TM } \\
& \text { Wilson } \\
& \text { MPC }
\end{aligned}
$$

Diagonal segments are produced by ties.

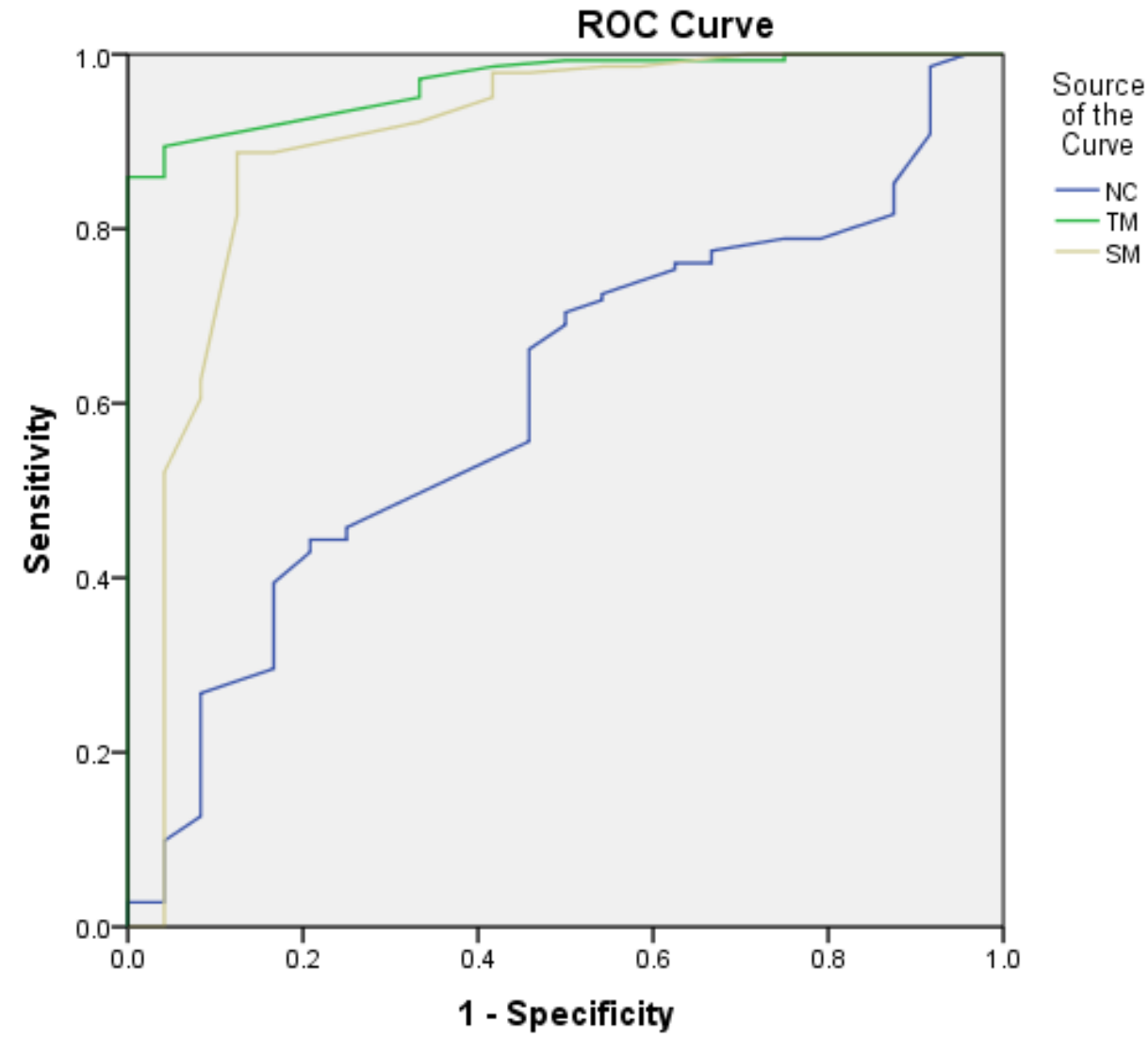

Diagonal segments are produced by ties.

NC/TM showed the highest sensitivity and specificity compared to Mallampati, Wilson score, Thyromental distance, Sternomental distance. NC/TM also shows a large area under the curve
(AUC) on the ROC curve. The cut-off point for difficult intubation for NC/TM was found to be 4.99 . 
TABLE: 04 TESTS FOR DIFFICULT INTUBATION : OBESE

\begin{tabular}{|l|l|c|c|c|c|c|c|c|}
\hline \multicolumn{2}{|l|}{} & sensitivity & specificity & PPV & NPV & PLR & NLR & Accuracy \\
\hline NC/TM & $\geq 4.99$ & 91.70 & 95.10 & 75.90 & 98.50 & 18.59 & 0.09 & 94.50 \\
\hline MPC & $\geq$ III & 70.80 & 78.90 & 36.17 & 94.17 & 3.35 & 0.37 & 77.70 \\
\hline $\begin{array}{l}\text { Wilson } \\
\text { score }\end{array}$ & $\geq 2$ & 58.30 & 86.60 & 42.40 & 92.40 & 4.35 & 0.48 & 82.50 \\
\hline NC $(\mathrm{cm})$ & 44.1 & 54.10 & 66.20 & 21.30 & 89.50 & 1.60 & 0.69 & 64.40 \\
\hline TM $(\mathrm{cm})$ & $\leq 9.3$ & 95.80 & 88.70 & 58.90 & 99.20 & 8.51 & 0.04 & 89.70 \\
\hline SM $(\mathrm{cm})$ & $\leq 16.45$ & 87.50 & 88.70 & 56.70 & 97.60 & 7.77 & 0.14 & 88.50 \\
\hline
\end{tabular}

In our study, Thyromental distance and Neck circumference to Thyromental distance ratio showed to be airway assessment tests with good sensitivity. NC/TM also had very high specificity and positive likelihood ratio( PLR) and therefore it is a clinical test with good accuracy.

TABLE: 05 UNIVARIATE ANALYSIS COMPARING NON-OBESE PATIENTS WITH IDS SCORE $\geq 5$ AND $<5$

\begin{tabular}{|c|c|c|c|c|c|c|}
\hline & \multicolumn{4}{|c|}{ IDS } & \multirow{3}{*}{$\mathrm{t}$} & \multirow{3}{*}{$\mathrm{p}$} \\
\hline & \multicolumn{2}{|c|}{$\geq 5(\mathrm{~N}=12)$} & \multicolumn{2}{|c|}{$<5(\mathrm{~N}=154)$} & & \\
\hline & mean & sd & mean & sd & & \\
\hline Age in years & 48.74 & 14.27 & 51.92 & 9.87 & 0.756 & 0.451 \\
\hline Weight in $\mathrm{Kg}$ & 62.82 & 7.66 & 60.75 & 11.38 & 0.87 & 0.386 \\
\hline Height in $\mathrm{cm}$ & 165.14 & 8.35 & 165.33 & 12.05 & 0.073 & 0.942 \\
\hline BMI in $\mathrm{kg} / \mathrm{m}^{2}$ & 23.05 & 2.02 & 22.04 & 1.67 & 1.686 & 0.094 \\
\hline $\mathrm{NC}$ in $\mathrm{cm}$ & 37.79 & 4.26 & 37.14 & 5.83 & 0.496 & 0.62 \\
\hline $\mathrm{TM}$ in $\mathrm{cm}$ & 11.32 & 1.62 & 8.88 & 2.86 & 4.688 & $<0.001$ \\
\hline $\mathrm{NC} / \mathrm{TM}$ & 3.4 & 0.59 & 4.62 & 1.56 & 5.826 & $<0.001$ \\
\hline $\mathrm{SM}$ in $\mathrm{cm}$ & 19.44 & 1.89 & 16.82 & 4.19 & 4.133 & $<0.001$ \\
\hline $\begin{array}{l}\text { Mouth opening in } \\
\mathrm{cm}\end{array}$ & 5.38 & 0.43 & 5.29 & 0.31 & 0.956 & 0.341 \\
\hline
\end{tabular}


ROC CURVE ANALYSIS OF SCREENING TESTS FOR DIFFICULT INTUBATION IN NON-OBESE

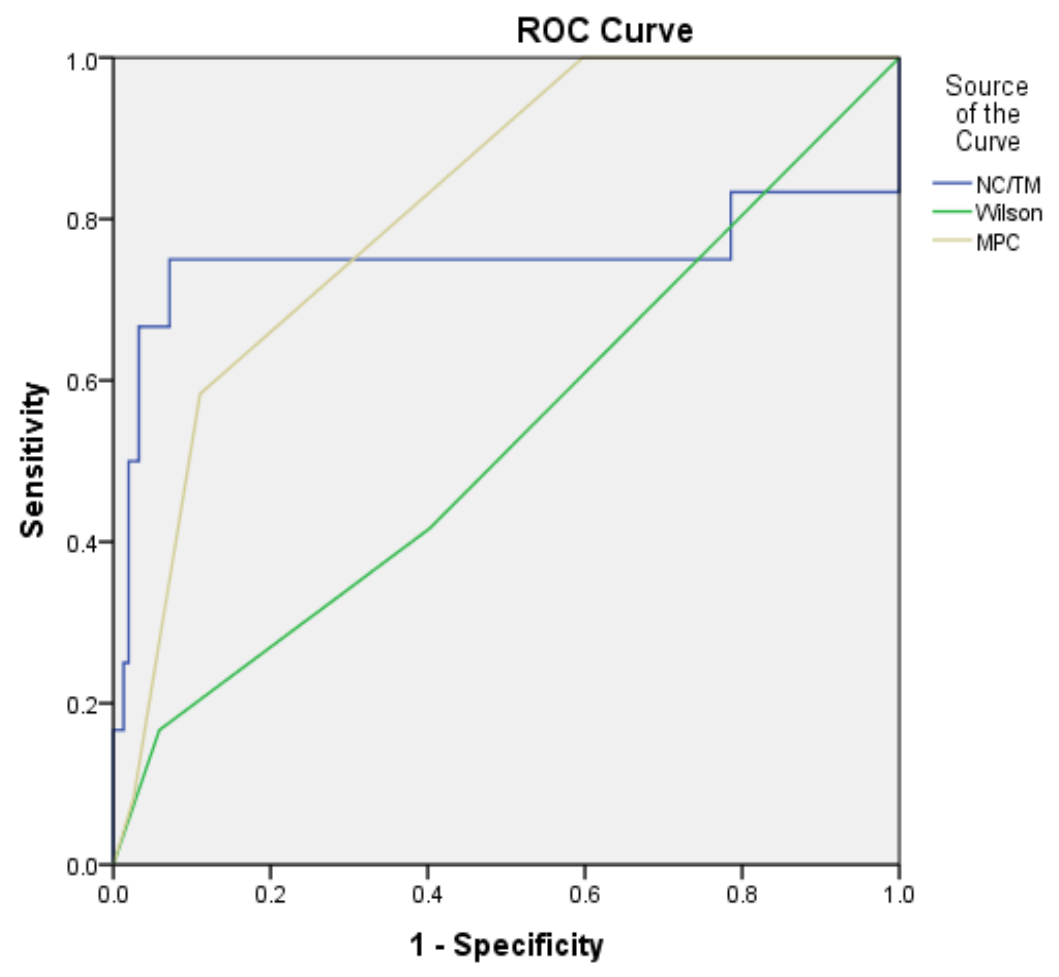

Diagonal segments are produced by ties.

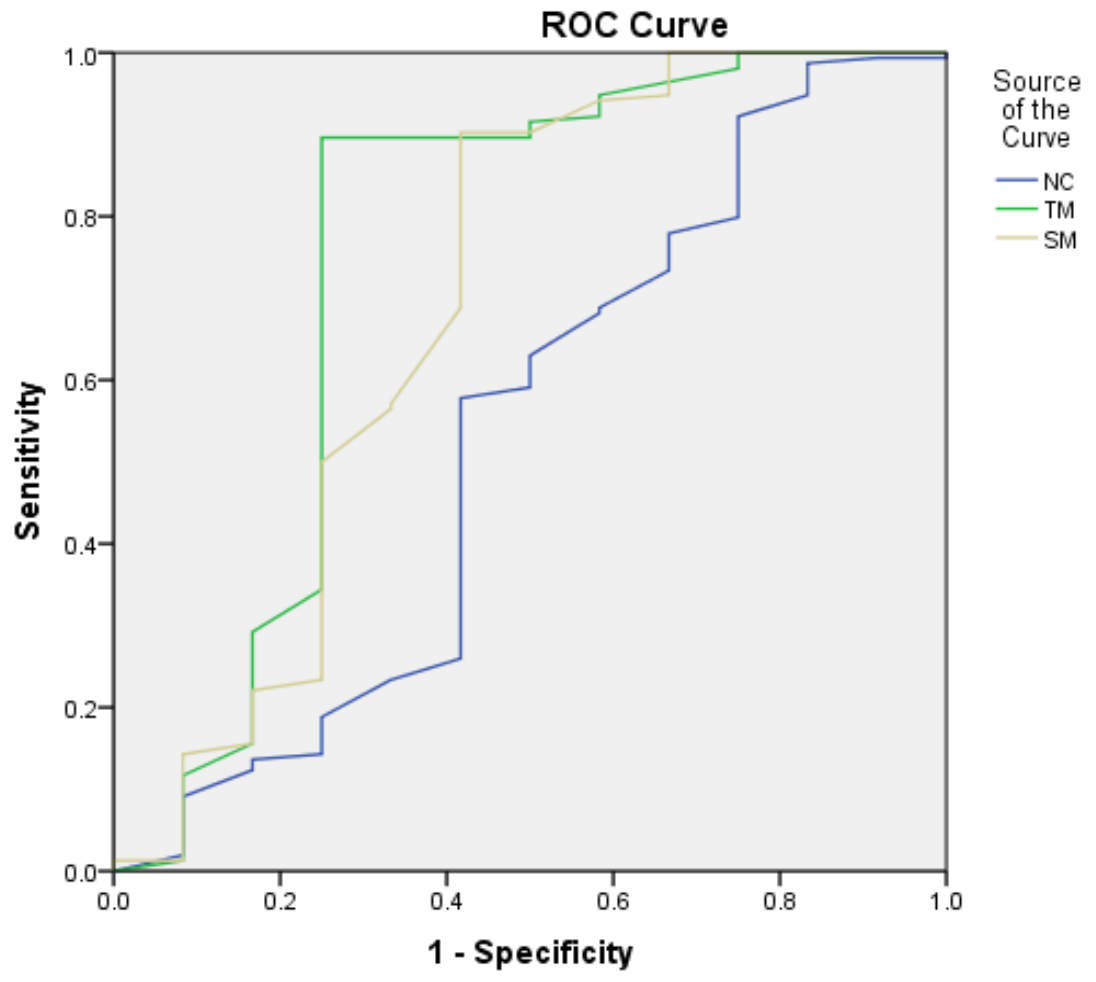

Diagonal segments are produced by ties.

At a cut-off of 4.192 neck circumference to thyromental distance ratio had very high specificity. Thyromental distance had a high specificity of $88 \%$. Both neck circumference to thyromental distance ratio and thyromental distance had a sensitivity of $75 \%$ which was greater than Modified Mallampati classification, neck circumference and sternomental distance. 
TABLE 06 TESTS FOR DIFFICULT INTUBATIO: NON-OBESE

\begin{tabular}{|l|l|c|c|c|c|c|c|c|}
\hline \multicolumn{2}{|l|}{ TEST } & sensitivity & specificity & PPV & NPV & PLR & NLR & Accuracy \\
\hline NC/TM & $\geq 4.1$ & 75.00 & 92.90 & 45.00 & 97.90 & 10.50 & 0.27 & 91.50 \\
\hline MPC & $\geq$ III & 58.30 & 89.00 & 29.10 & 96.40 & 5.28 & 0.47 & 96.70 \\
\hline NC & $\geq 37.6$ & 58.30 & 57.70 & 9.70 & 94.60 & 1.38 & 0.72 & 57.80 \\
\hline TM & $\leq 9.4$ & 75.00 & 88.30 & 33.30 & 97.80 & 6.41 & 0.28 & 87.30 \\
\hline SM & $\leq 17.5$ & 58.30 & 87.70 & 26.90 & 96.40 & 4.75 & 0.47 & 85.60 \\
\hline
\end{tabular}

NC/TM had very high specificity and positive likelihood ratio. Thyromental distance had a specificity of $88.3 \%$ and sensitivity of $75 \%$. Modified Mallampati classification had low sensitivity and positive likelihood ratio.

\section{DISCUSSION}

According to the literature, the incidence of difficult intubation is $1.5-8.5 \%{ }^{11}$ There are several screening tests for difficult intubation but the value is limited when a single test is used ${ }^{1,12}$. There are also several scoring systems incorporating several variables ${ }^{3}$. But most of these tests are very time consuming.

The are several studies showing that difficult intubation incidence is more in the obese compared with non obese with rate of difficult laryngoscopy ranging from $12-15.8 \%,{ }^{1,13,14}$.Our study considered 166 obese and 166 non obese patients and the incidence of difficult intubation was $14.5 \%$ in the obese group and $7.2 \%$ in the non obese group.

Multiple studies ${ }^{1,13,15}$ have shown that BMI alone does not offer any predictive value for difficult intubation. In our study, although obese patients had higher IDS, the grade of obesity which influences difficult intubation could not be assessed due to a limited number of patients with $\mathrm{BMI}>35$. Gonzalez ${ }^{16}$ and colleagues in their study found that intubation was difficult in obese with BMI >30 and that a large neck circumference would predict potential intubation problems .Ezri et al. ${ }^{14}$ used ultrasound to quantify neck soft tissue at the level of the vocal cords and suprasternal notch and demonstrated that, in an obese population, the best predictor of difficult intubation was distribution of fat in these areas.
Horner et al. demonstrated that more fat was present in areas surrounding the collapsible segments of the pharynx in patients with OSA syndrome ${ }^{17}$ by using magnetic resonance imaging measurements. So distribution of fat in specific neck areas, especially the anterior neck, may provide a better suggestion of difficult intubation than neck circumference. NC/TM was considered as a variable considering these findings. The NC/TM was significantly higher in obese patients with difficult intubation with a mean of 5.53 (SD 0.91 ) compared to non-obese 4.62 ( SD 1.56). Our study shows that NC/TM ratio, with a relatively large area under the curve on ROC and fair sensitivity and specificity at cut- off 4.99 , is a better airway assessment test for predicting difficult intubation in the obese. The positive predictive value was $75.9 \%$ and negative predictive value $98.5 \%$. In the non obese patients, the NC/TM ratio had a lower sensitivity of $75 \%$ at cut-off 4.192 and a positive predictive value of only $45 \%$.

Neck circumference cut-off values have been done in several studies with several different values obtained each time ${ }^{18}$. Hiremathe ${ }^{19}$ and colleagues in their study showed that neck circumference was not associated with difficult intubation. In our study population, NC did not have a significance in predicting difficult intubation. In the obese group, area under the curve on ROC was only .606 and at a cut -off of $44.1 \mathrm{~cm}$ the sensitivity was only $54.1 \%$ and specificity $66.2 \%$. The positive predictive value was low, $21.3 \%$. In the non-obese group, at a cut off of 37.65 , NC had very low sensitivity, postive predictive value. 
A meta-analysis by Lee A and colleagues revealed that modified Mallampati classification had a poor prognostic value to identify difficult intubation $^{.12}$. In our study, in the obese patients, at a cut-off of Mallamapti class III, the sensitivity was found to be $70.8 \%$ and positive likelihood ratio of 3.35.In the non-obese patients, at a cut-off Class III (with area under the curve on ROC was.817) , the sensitivity was only $58.3 \%$ ,specificity $89 \%$ and accuracy $96.7 \%$.In the metaanalysis of 55 studies involving a total of 177088 patients by Lundstrom et $\mathrm{al}^{20}$, only $35 \%$ of patients with a difficult intubation were identified as Mallampati III or IV and they concluded that the modified Mallampati is inadequate as a standalone test of a difficult laryngoscopy or intubation. In this study the positive likelihood ratio in the obese was 3.35 and non -obese patients it was 5.28. Iohom et al. ${ }^{21}$ also stated that rather than using the Mallampati classification alone, using other airway evaluation tests together is more useful in predicting difficult intubation.

Age between 40 and 59 years can carry a risk for difficult intubation ${ }^{22}$. In the obese group $33.3 \%$ patients with IDS $\geq 5$ were more than 51-60 years. Osteoarthritic changes could be one reason for this. In the study by Hyoung-Yong Moon et $\mathrm{al}^{23}$ it was shown that compared to young individuals, middle-aged or elderly adults are likely to experience more difficulty in endotracheal intubation as head and neck movement, thyromental distance, and interincisor gap are decreased and the grade of dentition, Mallampati score and cervical joint rigidity are increased.

All patients in our study group had a mouth opening $>3.8 \mathrm{~cm}$. A mouth opening of $<3.8 \mathrm{~cm}$ predicts difficult airway ${ }^{24}$ In our study, there was no significant difference in mouth opening between the difficult intubation groups in obese and non-obese patients.

Wilson's score ${ }^{25}$ compares several factors. Higher the risk score, greater the accuracy of prediction with a lower proportion of false positive ${ }^{24}$. None of the patients in our study group had a Wilson risk sum score more than 5. At a cut-off of 2 , Wilson's score had a low sensitivity and low positive predictive value and high negative predictive value in the obese group. In the non obese, there was no significant association between Wilson score and IDS

Thyromental distance varies with patient $\operatorname{size}^{26}$. The accuracy of thyromental distance as a predictor for difficult airway has been subjected to previous scrutiny. Racial difference also influences thyromental distance as a predictor of difficult laryngoscopy ${ }^{27}$.Turkan et al in their study found that the mean thyromental distances were $9.9 \pm 1.4 \mathrm{~cm}$ in male patients versus $9.7 \pm 1.6 \mathrm{~cm}$ in female patients $(\mathrm{P}<0.05)^{28}$. In our study, the mean thyromental distance in obese patients was $10.28 \mathrm{~cm}$ (SD1.51) and $11.14 \mathrm{~cm}$ (SD1.84) in the non-obese patients. In our study, thyromental distance was related to difficult intubation in both obese and non-obese patients. In the obese patients, it was found to have a high sensitivity of $95.8 \%$, specificity $88.7 \%$, accuracy of $89.7 \%$ and a positive likelihood ratio of 8.51 . In non-obese patients, the sensitivity was lower.

Studies addressing importance of Sternomental distance are relatively few ${ }^{29}$. In the study by Turkan and colleagues, younger patients (20-30 years) and male patients had longer mean sternomental distance measurements. Mean sternomental distances were $17.8 \pm 2.4 \mathrm{~cm}$ in male patients versus $16.3 \pm 2.3 \mathrm{~cm}$ in female patients ( $\mathrm{P}$ $<0.01)^{28}$. In our study, the mean sternomental distances were 17.33 (SD 4.92) in the obese patients and 19.25 (SD 2.22) in the non-obese. Sternomental distance was related to difficult intubation in the non-obese patients but with low sensitivity of $58.3 \%$, sensitivity of $87.7 \%$ and accuracy $85.6 \%$.

To conclude, our study showed that difficult intubation was higher in obese patients compared to non-obese. Neck circumference to thyromental distance ratio was found to have very high sensitivity, specificity and positive likelihood ratio in the obese group at a cut-off of $\geq 4.99$. Therefore, it may be used as a screening test for predicting difficult intubation .

This study has several limitations. In order to study the incidence of severe intubation 
difficulty a large study population is required. Due to constraints of time the study population was limited to 166 in each group. This may have been responsible for the lack of statistical significance in some of the results.

Although the anaesthesiologists who performed the intubations were unaware of the main aims and purposes of the study, they could have recognized the patients characteristics in the operating room. Therefore it was impossible to maintain complete blindness

Thirdly, patient position may have influenced the incidence of difficult intubation. In this study, the sniff position was maintained initially for all patients. This may have affected the study results. And also Macintosh No. 3 laryngoscopic blade was used for the first laryngoscopy in each case which may have been inappropriate for some patients as a first choice. The operator should have decided the blade size depending on patient characteristics.

\section{CONCLUSION}

The major findings of this study

a) Difficult intubation defined by IDS were common in obese patients compared to non-obese.

b) Neck circumference to thyromental ratio was significantly higher in the obese patients. Neck circumference to thyromental distance ratio $\geq 4.99$ yielded a very high sensitivity, specificity, and positive likelihood ratio in the obese group. Therefore, it may be used as a test for predicting difficult intubation in the obese.

\section{BIBLIOGRAPHY}

1. Shiga T,Wajima Z, Inoue T, Sakamoto A. Predicting difficult intubation in apparently normal patients. Anesthesiology 2005 Aug;103(2):429-37.

2. Samsoon GL, Young JR. Difficult tracheal intubation: A retrospective study. Anaesthesia 1987 May;42(5):487-90

3. Wilson ME, Spiegelhalter D, Robertson JA, Lesser P. Predicting difficult intubation. Br J Anaesth 1988 Aug;61 (2): 211-6

4. Langeron O, Masso E, Huraux C, Guggiari M, Bianchi A, Coriat P, et al. Prediction of difficult mask ventilation. Anesthesiology 2000 May;92(5):1229-36

5. Cormack RS, Lehane J. Difficult tracheal intubation in obstetrics. Anaesthesia1984 Nov;39(11):1105-11

6. Smita Prakash, Amitabh Kumar, Shyam Bhandari, ParulMullick, Rajvir Singh,1 and Anoop Raj Gogia. Difficult laryngescopy and intubation in the Indian population: An assessment of anatomical and clinical risk factors. Indian $\mathrm{J}$ Anaesth. 2013 Nov-Dec; 57(6): 569-575.

7. Adnet F, Borron SW, Racine SX, Clemessy JL, Fournier JL, PlaisanceP, et al. The Intubation Difficulty Scale (IDS): Proposal and evaluation of a new score characterizing the complexity of endotracheal intubation. Anesthesiology 1997 Dec;87(6):1290-7

8. W. H. Kim1, H. J. Ahn1, C. J. Lee1, B. S. Shin1, J. S. Ko1, S. J. Choil and S. A. Ryu. Neck circumference to thyromental distance ratio: a new predictor of difficult intubation in obese patients Br. J. Anaesth. 2011; May;106(5):743-8

9. WHO/IASO/ITO. Asia Pacific Perspective: Redefining obesity and its treatment World Health Organization, Western Pacific Region;2000

10. Sellick BA. Cricoid pressure to control regurgitation of stomach contents during induction of anaesthesia.Lancet1961;2: 404- 618 .

11. Finucane, Brendan T., Tsui, Ban C.H., Santora, Albert. Principles of Airway Management, $4^{\text {th }}$ ed. 2011, Evaluation of the airway

12. Lee A, Fan LT, Gin T, Karmakar MK, NganKee WD. A systemicreview (metaanalysis) of the accuracy of the Mallam patitests to predict the difficult airway. Anesth Analg2006;102: 1867-78 
13. Juvin P1, Lavaut E, Dupont H, Lefevre P, Demetriou M, Dumoulin JL, Desmonts JM. Difficult tracheal intubation is more common in obese than in lean patients. Anaesthesia analogue 2003; 97:595-600

14. Ezri T, Gewürtz G, Sessler DI, Medalion B, Szmuk P, Hagberg C, Susmallian S. Prediction of Difficult Laryngoscopy in Obese Patients by Ultrasound Quantification of Anterior Neck Soft Tissue. Anaesthesia 2003 Nov; 58(11): 1111-1114.

15. Lundstrøm LH1, Møller AM, Rosenstock C, Astrup G, Wetterslev J. High body mass index is a weak predictor for difficult and failed tracheal intubation: a cohort study of 91,332 consecutive patients scheduled for direct laryngoscopy registered in the Danish Anaesthesia Database.

16. Gonzalez, Hélène MD; Minville, Vincent MD, MSc; Delanoue, Khedija MD; Mazerolles, Michel MD; Concina, Dominique MD; Fourcade, Olivier MD, PhD.The Importance of Increased Neck Circumference to Intubation Difficulties in Obese Patients. Anesthesia \& Analgesia: April 2008 - 106 - Issue 4

17. R.L. Horner, R.H. Mohiaddin, D.G. Lowell, S.A. Shea, E.D. Burman, D.B. longmore, A. Guz Sites and sizes of fat deposits around the pharynx in obese patients with obstructive sleep apnoea and weight matched controls EurResp J, 1989: 613-622

18. Brodsky JB1, Lemmens HJ, Brock-Utne JG, Vierra M, SaidmanLJ.: Morbid obesity and tracheal intubation. Anaesthesia analogue 2002 Mar;94(3):732-6

19. A.S.Hiremath, D.R.Hillman, A.1.James, W.J. Noffsinger,P.R.Platt. Relation between difficult tracheal intubation and obstructive sleep apnea. BJA 1998;80:606-611

20. L. H. Lundstrøm, M. Vester-Andersen1, A. M. Møller1, S. Charuluxananan3, J. L'Hermite4 and J. Wetterslev. Poor prognostic value of the modified
Mallampati score: a meta-analysis involving 177088 patients .The Danish Anaesthesia Database

21. G. Iohom a1c1, M. Ronayne a1 and A. J. Cunningham a1: European Journal of Anaesthesiology January 2003

22. Rose DK, Cohen MM. The airway: problems and predictions in 18,500 patients. Can J Anaesth 1994; 41:372-83.

23. Hyoung-Yong Moon, Chong WhaBaek, Jin-Seo Kim, Gill Hoi Koo, Jin-Yun Kim et al. The causes of difficult tracheal intubation and preoperative assessments in different age groups. Korean J Anesthesiol 2013 April 64(4): 308-314

24. Dr. Sunanda Gupta1 Dr. Rajesh Sharma KR2 Dr. DimpelJain :Airway Assessment : Predictors of difficult airway. Indian $\mathrm{J}$. Anaesth. 2005: 49(4): 257-262. 5

25. McGill IW. Technique in endotracheal anaesthesia. Br Med J 1930; 2:817.

26. Schmitt HJ, Kirmse M, Radespiel-Troger M; Ratio of patient's height to thyromental distance improves prediction of difficult laryngoscopy. Anaesthesia and Intensive Care 2002; 30: 763-5.

27. P. A. Baker, A. Depuydt and J. M. D. Thompson Thyromental distance measurement - fingers don't rule .Anaesthesia Volume 64 August 2009 , Issue 8 , pages $878-882$

28. Türkan, Selma MD,;Ateş, Yeşim MD,; Cuhruk, Handan MD; Tekdemir, İbrahimMD.Should We Reevaluate the Variables for Predicting the Difficult Airway in Anesthesiology?. Anesthesia \& Analgesia: May 2002 - Volume 94 - Issue $5: 1340-1344$.

29. S. Shailaja, S. M. Nichelle, A. Kishan Shetty, and B. Radhesh Hegde .Comparing ease of intubation in obese and lean patients using intubation difficulty scale Anesth Essays Res. 2014 May-Aug; 8(2): 168-174. 